\title{
Usage of Tacrolimus and Mycophenolic Acid During Conception, Pregnancy, and Lactation, and Its Implications for Therapeutic Drug Monitoring: A Systematic Critical Review
}

\author{
Hoang Lan Le, BSc,* Marith I. Francke, BSc, †t Louise M. Andrews, PharmD, PhD, $\S$ \\ Brenda C. M. de Winter, PharmD, PhD, * Teun van Gelder, MD, PhD, $\mid$ and Dennis A. Hesselink, MD, PhD †t
}

\begin{abstract}
Background: Conception, pregnancy, and lactation following solid organ transplantation require appropriate management. The most frequently used immunosuppressive drug combination after solid organ transplantation consists of tacrolimus (Tac) plus mycophenolic acid (MPA). Here, the effects of Tac and MPA on fertility, pregnancy, and lactation are systematically reviewed, and their implications for therapeutic drug monitoring (TDM) are discussed.
\end{abstract}

Methods: A systematic literature search was performed (August 19, 2019) using Ovid MEDLINE, EMBASE, the Cochrane Central Register of controlled trials, Google Scholar, and Web of Science, and 102 studies were included. Another 60 were included from the reference list of the published articles.

Results: As MPA is teratogenic, women who are trying to conceive are strongly recommended to switch from MPA to azathioprine. MPA treatment in men during conception seems to have no adverse effect on pregnancy outcomes. Nevertheless, in 2015, the drug label was updated with additional risk minimization measures in a pregnancy prevention program. Data on MPA pharmacokinetics during pregnancy and lactation are limited. Tac treatment during conception, pregnancy, and lactation seems to be safe in terms of the health of the mother, (unborn) child, and allograft. However, Tac may

Received for publication February 11, 2020; accepted April 11, 2020.

From the Departments of *Hospital Pharmacy and †Internal Medicine, Erasmus MC, University Medical Center Rotterdam, Rotterdam; †Rotterdam Transplant Group, Rotterdam; §Department of Hospital Pharmacy, Meander Medical Center, Amersfoort; and $q$ Department of Clinical Pharmacy and Toxicology, Leiden University Medical Center, Leiden, The Netherlands.

H. L. Le and M. Francke contributed equally to the writing of this manuscript.

T. van Gelder has received lecture fees and grant support from Chiesi Pharmaceuticals and Astellas Pharma, and consulting fees from Roche Diagnostics, Aurinia, Vitaeris, Astellas, and Novartis. D. A. Hesselink has received consulting and lecture fees, as well as grant support from Astellas Pharma, Chiesi Farmaceutici SpA, and Novartis Pharma. L.M. Andrews and B.C.M. de Winter declare no conflict of interest.

Supplemental digital content is available for this article. Direct URL citations appear in the printed text and are provided in the HTML and PDF versions of this article on the journal's Web site (www.drug-monitoring. com).

Correspondence: Dennis A. Hesselink, MD, PhD, Division of Nephrology \& Renal Transplantation, Department of Internal Medicine, Erasmus MC, University Medical Center Rotterdam, Room Rg-527, P.O. Box 2040, 3000 CA Rotterdam, the Netherlands (e-mail: d.a.hesselink@ erasmusmc.nl).

Copyright (C) 2020 Wolters Kluwer Health, Inc. All rights reserved. increase the risk of hypertension, preeclampsia, preterm birth, and low birth weight. Infants will ingest very small amounts of Tac via breast milk from mothers treated with Tac. However, no adverse outcomes have been reported in children exposed to Tac during lactation. During pregnancy, changes in Tac pharmacokinetics result in increased unbound to whole-blood Tac concentration ratio. To maintain Tac concentrations within the target range, increased Tac dose and intensified TDM may be required. However, it is unclear if dose adjustments during pregnancy are necessary, considering the higher concentration of (active) unbound Tac.

Conclusions: Tac treatment during conception, pregnancy and lactation seems to be relatively safe. Due to pharmacokinetic changes during pregnancy, a higher Tac dose might be indicated to maintain target concentrations. However, more evidence is needed to make recommendations on both Tac dose adjustments and alternative matrices than whole-blood for TDM of Tac during pregnancy. MPA treatment in men during conception seems to have no adverse effect on pregnancy outcomes, whereas MPA use in women during conception and pregnancy is strongly discouraged.

Key Words: mycophenolic acid, pregnancy, tacrolimus, therapeutic drug monitoring, transplantation

(Ther Drug Monit 2020;42:518-531)

\section{INTRODUCTION}

In 1958 , the first pregnancy after solid organ transplantation (SOT) occurred. ${ }^{1}$ The pregnant woman had received a kidney from her identical twin sister, and therefore, no immunosuppression was required to prevent rejection. Two years after the transplantation, a healthy boy weighing $3300 \mathrm{~g}$ was delivered by cesarean section. ${ }^{2,3}$ Since this first successful case, pregnancy after kidney transplantation has become more common and has also occurred in recipients of liver, heart, pancreas, and lung transplants. ${ }^{4-9}$

Women with end-stage organ failure often experience infertility. Following a successful organ transplantation, fertility is usually restored rapidly (within an average of 6 months). ${ }^{10,11}$ SOT recipients of childbearing age may therefore consider pregnancy but should be counseled about the risks. In general, SOT recipients are advised to postpone conception until the graft function has stabilized. ${ }^{12}$

Despite the increasing numbers of successful pregnancies following SOT, pregnancy in a transplant recipient is a special 
situation that requires appropriate management. ${ }^{13}$ Unlike the first reported pregnancy after SOT, most pregnant women will be treated with immunosuppressive drugs during pregnancy and lactation. Here, the use of the most frequently used immunosuppressive drug combination following SOT, namely, tacrolimus (Tac) plus mycophenolic acid (MPA), during conception, pregnancy, and lactation is systematically reviewed. The effects of these drugs on male and female fertility, their teratogenicity and pharmacokinetics during pregnancy and lactation, and implications for therapeutic drug monitoring (TDM) are discussed. transplantation" (see Supplemental Digital Content 1 for search strategy, http://links.lww.com/TDM/A406). The search yielded 3083 articles. After duplicates were removed, 2351 articles were reviewed as described previously. ${ }^{14}$ After exclusion of irrelevant articles (after the title and abstract were read), 337 articles remained, of which the relevant 102 articles were included in this review (Fig. 1). Examination of the reference list of the studies identified further studies $(\mathrm{n}=$ 60). Only full-length articles published in English and in peerreviewed journals after the year 1990 were included. Articles not available at our institution were excluded.

\section{METHODS}

A systematic literature search was performed (August 19, 2019) using Ovid MEDLINE, EMBASE, the Cochrane Central Register of controlled trials, Google Scholar, and Web of Science. The search terms included "tacrolimus," "mycophenolic acid," "pregnancy," "lactation," and "kidney

\section{TACROLIMUS}

\section{Effects on Fertility}

End-stage organ failure is associated with disturbed function of the hypothalamic-pituitary-gonadal (HPG) axis

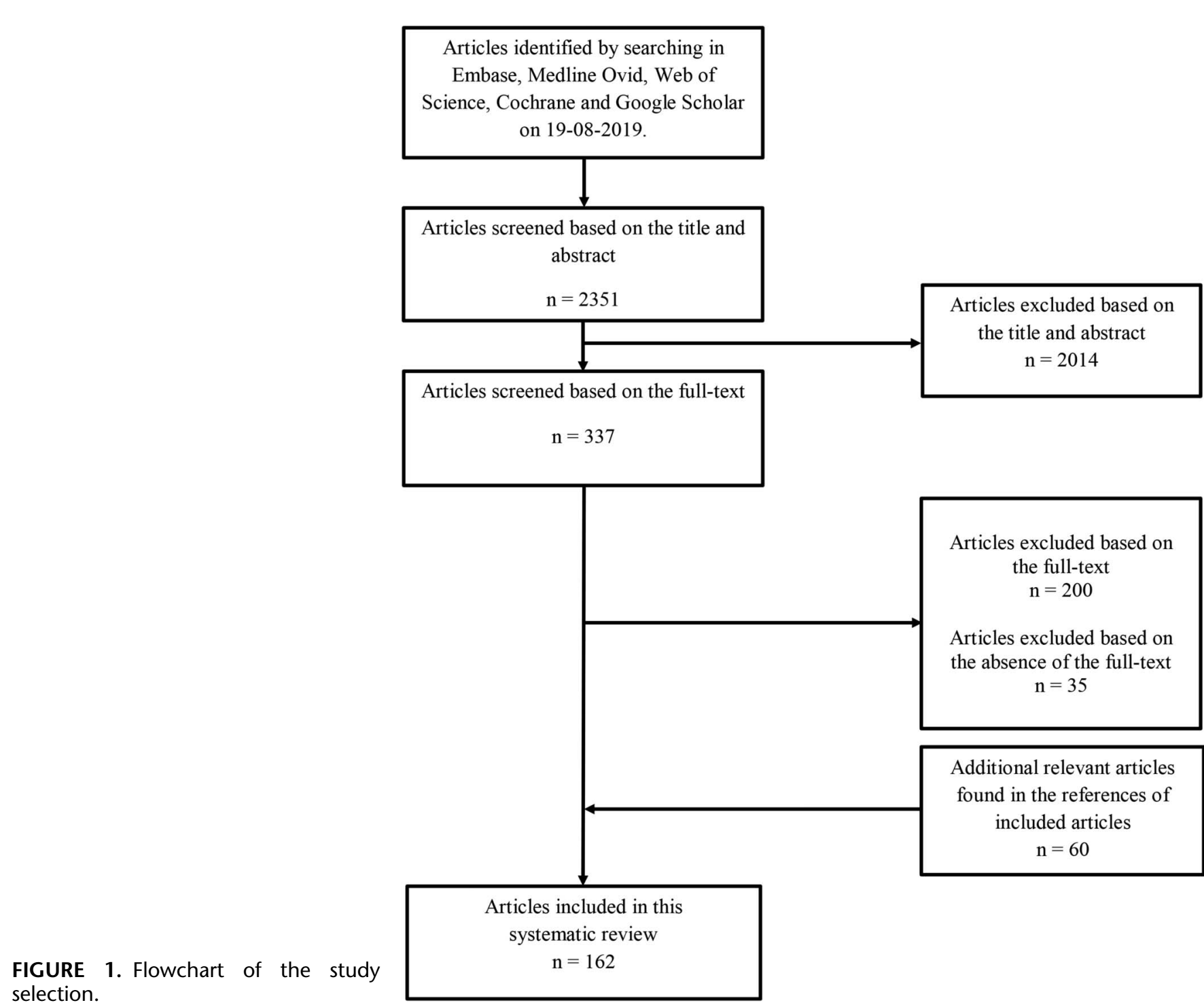

selection. 
and is characterized by increased plasma concentrations of follicle-stimulating hormone (FSH), luteinizing hormone $(\mathrm{LH})$, and prolactin. Moderate reduction in glomerular filtration rate (eGFR) can increase the concentrations of gonadotrophin hormones and prolactin. Moreover, testosterone and estradiol concentrations are lower in patients with end-stage renal disease than in healthy controls. ${ }^{15}$ These disturbances can result in infertility in both male and female patients. ${ }^{15,16}$ Successful transplantation improves FSH, LH, testosterone, estradiol, and prolactin concentrations, but the use of Tac may counteract the normalization of the levels of these hormones. ${ }^{16-19}$

\section{Effects on Male Fertility}

In animals, Tac affects sperm count, motility, and morphology in a dose-dependent manner. ${ }^{20-22}$ In addition, morphological alterations of the seminiferous tubules and peritubular cells and reduction of Sertoli cells and germ cells have been reported in rats treated with Tac. ${ }^{22,23}$ Moreover, Tac use has been associated with embryo-lethal effects and adverse reproductive outcomes. ${ }^{24}$ However, Tac usage does not affect serum testosterone concentrations nor the morphology of Leydig cells. ${ }^{25}$

In humans, studies on the effect of Tac on male fertility are limited. ${ }^{11}$ Table 1 shows studies on gonadal and sexual function in a total of 140 kidney transplant recipients. Tauchmanova et al studied the HPG axis after successful renal transplantation in patients receiving prednisone with calcineurin inhibitors [CNIs; cyclosporin (CsA) or Tac] or mycophenolate mofetil (MMF) or azathioprine (AZA). They reported that 15-86 months after successful renal transplantation, abnormalities in the HPG axis were still present in $69 \%$ of the men. The testosterone concentration in men treated with CNIs was $10.4 \pm 3.1 \mathrm{nmol} / \mathrm{L}$, which is below the normal range $(12.1-31.0 \mathrm{nmol} / \mathrm{L})$. Testosterone concentration was significantly lower in men treated with CNIs than in those treated with MMF or AZA. Furthermore, dehydroepiandrosterone sulfate and androstenedione concentrations were significantly lower in the kidney transplant recipients receiving CNIs than in those receiving other immunosuppressive regimens. In this study, only patients with a fully functioning allograft were included, which explains the high eGFR values of these patients (median, $85 \mathrm{~mL} / \mathrm{min}$; ranging from 60 to 171 $\mathrm{mL} / \mathrm{min}$ ). Testosterone concentrations were significantly lower in renal allograft recipients with an eGFR level of $<85 \mathrm{~mL} / \mathrm{min}$ than in recipients with a eGFR level of $>85$ $\mathrm{mL} / \mathrm{min}$. The authors suggested an association between gonadal function and allograft function, instead of the immunosuppressive treatment. ${ }^{26}$

Tainio et $\mathrm{a}^{19}$ compared kidney transplant recipients using CNIs combined with AZA, MMF, or prednisolone with healthy control subjects. The kidney transplant recipients had significantly lower testosterone concentrations and significantly higher LH concentrations than those of the controls. FSH concentrations were not significantly different between the 2 groups. Testosterone concentrations were within the normal range.

Tondolo et $\mathrm{al}^{27}$ compared blood FSH, LH, and testosterone concentrations between patients receiving CNIs, sirolimus, and sirolimus plus CNI in addition to maintenance

TABLE 1. Studies Reporting the Testicular Endocrine Function, as Well as the Prostate, Testicular, or Semen Function

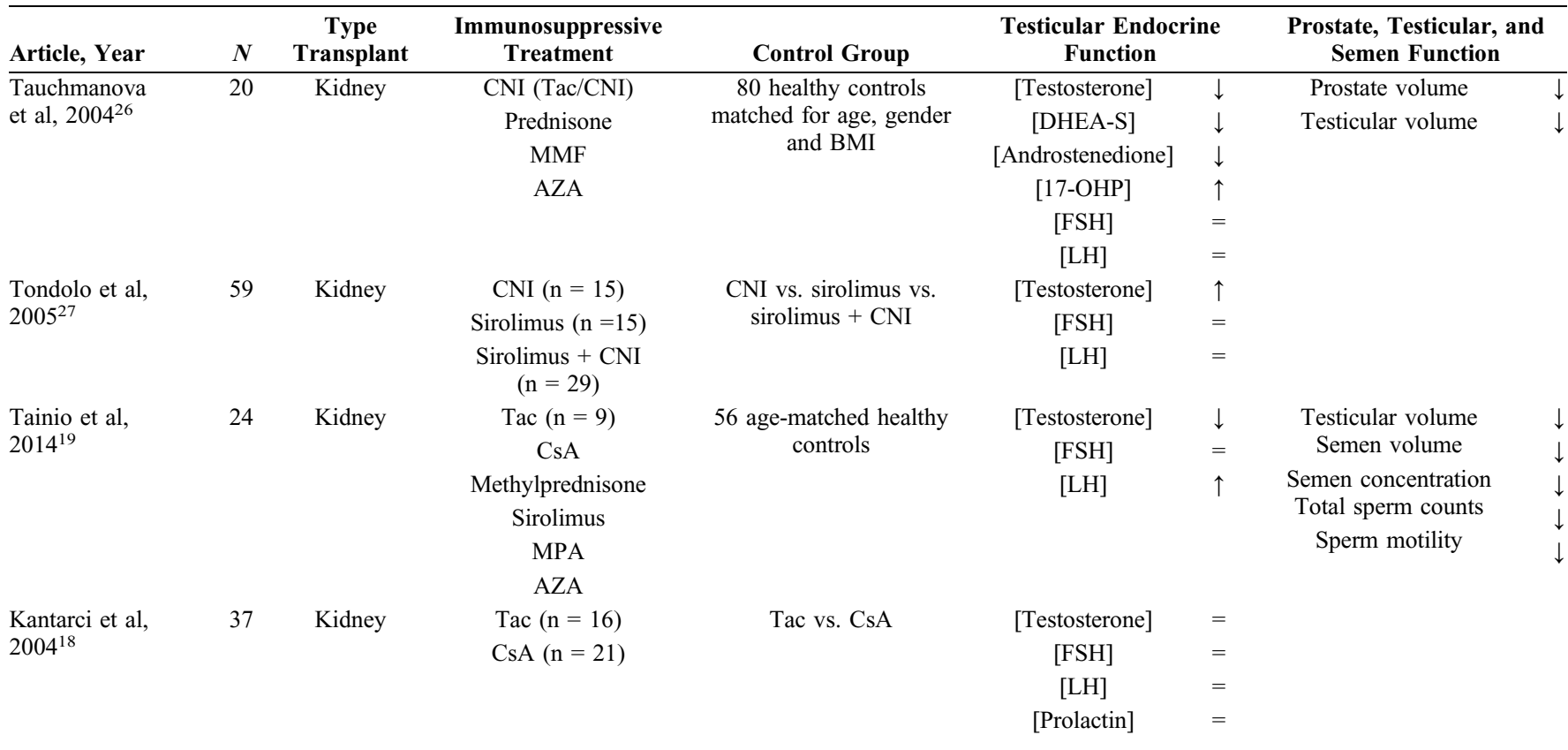

17-OHP, 17-a-hydroxyprogesterone; AZA, azathioprine; BMI, body mass index; CNI, calcineurin inhibitor; CsA, ciclosporin; DHEA-S, dehydroepiandrosterone sulphate; FSH, follicle stimulating hormone; Tac, tacrolimus. 
steroid therapy. Testosterone concentrations in men treated with CNIs was higher than that in men treated with sirolimus $(4.39 \pm 1.53 \mathrm{ng} / \mathrm{mL}$ versus $3.12 \pm 1.23 \mathrm{ng} / \mathrm{mL}$, respectively; $P<0.020$ ). No significant differences were observed in FSH and LH concentrations. ${ }^{27}$ Kantarci et al $^{18}$ found no differences in serum concentrations of FSH, LH, testosterone, and prolactin between kidney transplant recipients treated with either Tac or CsA. The concentrations of these hormones were also within the normal range.

Two studies investigated testicular volume and semen quality in transplant recipients receiving immunosuppressive drugs including Tac. Both studies reported smaller testicular volume and worse semen quality in renal allograft recipients using Tac than those in healthy men. Testicular volume was associated with low testosterone concentrations. ${ }^{26}$

Taken together, male fertility is at least partially restored after successful kidney transplantation, despite the use of immunosuppressive agents. The correction of infertility following transplantation depends on the immunosuppressive regimen. Especially, the use of the mammalian target of rapamycin inhibitors sirolimus and everolimus has been associated with impaired gonadal function in men. ${ }^{28,29}$ Tac use is associated with alterations in sperm count, motility, and morphology; low to normal testosterone concentrations and high to normal LH and FSH concentrations. However, these alterations seem to be caused in part by the kidney transplant function itself, and differences compared with other immunosuppressive regimens, which are less potent in terms of rejection prophylaxis, are small. Moreover, successful pregnancies fathered by men on Tac treatment have been reported. At this moment, Tac seems to be the best treatment option for male transplant recipients who wish to establish a family, considering both the fertility and allograft outcomes.

\section{Effects on Female Fertility}

Limited information is available regarding the effect of Tac on the fertility of female transplant recipients. Female fertility improves after transplantation. ${ }^{30-32}$ After transplantation, a decrease in the prevalence of amenorrhea and an increase in the regularity of the menstrual cycle has been reported in women who received CNI treatment. ${ }^{33}$

In female rats, tacrolimus treatment (at a dose of 3.2 $\mathrm{mg} / \mathrm{kg}$ ) was associated with increased embryo-fetal lethality and increased numbers of undelivered and nonviable pups. ${ }^{24}$ This experimental dose corresponds with 2.6-6.9 times the human clinical dose, which ranges from 0.075 to $0.2 \mathrm{mg} / \mathrm{kg} /$ $\mathrm{d}$ on an milligrams/square meter basis. ${ }^{24}$ Incomplete delivery of nonviable pups was observed at a dose of $1.0 \mathrm{mg} / \mathrm{kg}(0.8-$ 2.2 times the human clinical dose range at an milligrams/ square meter basis).

In humans, the effect of Tac on female reproductive health is unclear. Infertility rates seem to be higher than those in the general population. In a retrospective cohort study by Yaprak et al, ${ }^{34}$ which included 33 female renal allograft recipients on a different immunosuppressive regimen, 64\% of the women, who had actively been trying did not become pregnant within 1 year. This rate is higher than that in the general population, where it is estimated that among women trying to conceive, $16 \%$ fail to become pregnant within 1 year. ${ }^{35}$ In contrast, in a cohort of 148 female renal allograft recipients, 18 of 22 women $(81.8 \%)$ on Tac treatment who had actively been trying to become pregnant for 1 year did so. The women received Tac, an antimetabolite, and prednisolone as immunosuppressive therapy. ${ }^{36}$

In a regression analysis, Tac use in combination with MMF (compared with other treatment options) appeared to be a positive predictor of pregnancy within 1 year for female SOT recipients trying to conceive in addition to regular menstrual cycle and age. ${ }^{34}$

Based on the above findings, despite limited data, it appears that Tac treatment is associated with a higher to normal infertility rate among female transplant recipients.

\section{Pharmacokinetics of Tac}

\section{Pharmacokinetics in the Mother}

During pregnancy, there are several physiologic changes that can alter the pharmacokinetics of Tac. Theoretically, changes in Tac absorption, distribution, metabolism, and excretion during gestation may cause a lower whole-blood Tac concentration and a relatively higher unbound Tac concentration.

Tac absorption is dependent on the activity of the efflux transporter P-glycoprotein (P-gp or ABCB1), among other factors. ${ }^{37}$ Although P-gp activity in the kidney increases during pregnancy, ${ }^{38}$ it is unknown whether similar changes occur in intestinal P-gp activity.

Throughout pregnancy, the volume of distribution of Tac changes. ${ }^{39}$ This is caused by an almost $50 \%$ increase in maternal blood volume, ${ }^{40-42}$ a decreased red blood cell count, ${ }^{40,42}$ decreased plasma albumin concentration, ${ }^{39,40}$ and decreased $\alpha_{1}$-acid glycoprotein concentration throughout gestation. $^{43}$ These decreases in plasma protein concentrations occur especially during the second and third trimesters. ${ }^{40,41,44}$ Normally, less than $3 \%$ of Tac is unbound (free). The decrease in Tac binding sites on plasma proteins and erythrocytes (which contain high amounts of the Tac receptor FKbinding protein-12; FKBP-12) results in relatively high unbound Tac concentration. ${ }^{40}$

Unbound Tac concentrations were studied in female kidney transplant recipients during pregnancy $(\mathrm{n}=10)$ and compared with postpartum unbound Tac concentrations $(\mathrm{n}=$ 5 ) by Zheng et al. ${ }^{40}$ The target whole-blood predose Tac concentrations were maintained by TDM throughout gestation. As a result of the described pharmacokinetic changes and maintenance of the target Tac predose concentrations, a 2.7 times higher area under the plasma concentration-time curve (AUC) of unbound Tac $(0.44 \pm 0.19 \mathrm{ng} \cdot \mathrm{h} / \mathrm{mL}$ versus $0.16 \pm 0.06 \mathrm{ng} \cdot \mathrm{h} / \mathrm{mL} ; P=0.03)$ and a $112 \%$ higher unbound predose Tac concentration in blood $(0.018 \pm 0.010 \mathrm{ng} / \mathrm{mL}$ versus $0.009 \pm 0.003 \mathrm{ng} / \mathrm{mL}, P=0.02$ ) were observed in the $\mathrm{mid} /$ late pregnancy than those in the postpartum period. In both blood $(0.38 \pm 0.13 \%$ versus $0.19 \pm 0.07 \% ; P=0.002)$ and plasma $(5.4 \pm 0.7 \%$ versus $2.8 \pm 0.4 \% ; P=0.0007)$, a significantly higher proportion of unbound Tac was observed in the mid/late pregnancy than that in the postpartum period. ${ }^{40}$ 
The net result of the described changes is an increased unbound to whole-blood Tac ratio. As unbound Tac is considered pharmacologically active and only unbound drugs in plasma can migrate to the intracellular compartment and bind to their receptor, it was suggested that unbound Tac concentrations may correlate better with drug efficacy than whole-blood Tac concentrations. ${ }^{45}$ However, there are no pharmacodynamic data to support this hypothesis.

During pregnancy, Tac metabolism changes. After administration of several cytochrome P4503A (CYP3A) probe substrates (midazolam and dextromethorphan) to pregnant women, an increased oral clearance was observed, suggesting an increase in either intestinal or hepatic CYP3A activity (or both) during pregnancy. ${ }^{38,46}$ Indeed, when applying dose titration, the mean oral clearance $(\mathrm{CL} / \mathrm{F})$ based on whole-blood Tac concentrations was 39\% higher during pregnancy than that in the postpartum period $(47.4 \pm 12.6 \mathrm{~L} / \mathrm{h}$ versus $34.2 \pm 14.8 \mathrm{~L} / \mathrm{h} ; P<0.03) .{ }^{40}$ This decrease in Tac whole-blood concentrations can be partly attributed to increased CYP3A-mediated hepatic metabolism as a part of normal physiologic adaption. ${ }^{38,44,46}$ Multiple studies have reported Tac concentrations at different time points during pregnancy. ${ }^{39,40,47-50}$ Three of these studies concluded that an increase in Tac dosage was required to maintain the target concentration. ${ }^{48-50}$ In addition, the increase in the unbound Tac fraction in blood and plasma correlated with the Tac whole-blood $\mathrm{CL} / \mathrm{F}$ ratio $(\mathrm{r}=0.7, P=0.001$ and $\mathrm{r}=0.6, P$ $=0.007$, respectively). ${ }^{40}$ This correlation may be explained by the higher interaction of unbound Tac with CYP3A enzymes. 44

As Tac is excreted mainly via bile, the effects of changes in renal function $44,51,52$ and renal drug transporter activity $^{38}$ on Tac systemic clearance are likely to be limited. Together, changes in Tac absorption, distribution, metabolism, and excretion result in an increased unbound to whole-blood Tac concentration ratio in both blood and plasma. TDM using whole-blood concentrations may, therefore, underestimate the unbound Tac fraction. As unbound Tac is considered the fraction available for receptor binding, an increase in Tac dose during pregnancy might be unnecessary. However, because the optimal concentration of unbound Tac is unclear, and whole-blood Tac concentrations are measured in clinical practice, it might be safer to increase Tac dose and accept higher unbound Tac concentrations. However, it should be noted that, in theory, the higher free Tac fraction may increase the risk of Tac-related toxicity, including new-onset diabetes mellitus and hypertension. These complications may be difficult to distinguish from pregnancy-related hypertension (or preeclampsia) and gestational diabetes. ${ }^{53,54}$

\section{Pharmacokinetics in the Infant}

Tac can enter the fetal circulation through the placenta, ${ }^{47,55,56}$ resulting in the possibility of fetotoxic and teratogenic effects. Tac was found in infants' blood at concentrations of $50 \%-70 \%$ lower than that of the mother, measured within 3 days after birth (median = $1.15 \mathrm{ng} / \mathrm{mL}$ versus $0.4 \mathrm{ng} / \mathrm{mL}^{47}$ and median $=6.6 \mathrm{ng} / \mathrm{mL}$ versus $\left.1.1 \mathrm{ng} / \mathrm{mL}^{57}\right)$. This suggests that Tac was either cleared by the infant or that the placenta forms a protective barrier or both. Tac accumulation in placental tissue was observed both in vivo and ex vivo. ${ }^{55}$ Tac concentrations in the placenta were 2-56 times higher than that in cord blood (median $=2.8 \mathrm{ng}$ per $\mathrm{g}$ placenta versus $0.4 \mathrm{ng} / \mathrm{mL}$ in cord blood). ${ }^{47}$

P-gp is highly expressed in the placenta during early gestation, and it might actively transport Tac back into the maternal circulation. ${ }^{58}$ Zheng et al reported a venous umbilical cord Tac concentration of $6.6 \mathrm{ng} / \mathrm{mL}$, which corresponded with $71 \pm 18 \%$ of the maternal blood concentration $(9.0 \mathrm{ng} / \mathrm{mL})$. The venous umbilical cord plasma to maternal plasma Tac concentration and the venous cord unbound to maternal plasma Tac concentration ratios were $0.23(0.09 \mathrm{ng} / \mathrm{mL}$ versus $0.40 \mathrm{ng} / \mathrm{mL})$ and $0.19(0.003 \mathrm{ng} /$ $\mathrm{mL}$ versus $0.017 \mathrm{ng} / \mathrm{mL})$, respectively. ${ }^{59}$ Placental P-gp expression was the lowest at the end of gestation. Therefore, fetal exposure throughout gestation may be even lower than the concentrations found in infants immediately after birth. ${ }^{60}$

No studies have investigated the fetal volume of distribution of Tac. Fetal hematocrit was higher than maternal hematocrit; thus, the unbound fraction of Tac in the fetus is likely to be lower than that in the mother. ${ }^{40}$

Tac metabolism in the fetus may be minimal owing to low CYP3A4 and CYP3A5 expression in the fetal liver. The predominant enzyme is CYP3A7, which metabolizes Tac less efficiently than CYP3A4. ${ }^{44,61,62}$ During gestation, CYP3A7 may also act in the endometrium and placenta. From the first to the second trimester, CYP3A7 presence in the endometrium and placenta was found to increase. ${ }^{63}$ Little is known about the development and activity of CYP3A5. CYP3A5 expression may be independent of age, although a study suggested higher CYP3A5 expression in children than in adults. ${ }^{62,64}$ Kociszewaska-Najman et al measured the concentrations of the Tac metabolites 13-O-demethyl tacrolimus (13-DMT) and 15-O-demethyl tacrolimus (15-DMT) in cord blood. ${ }^{65}$ The mean concentration of Tac, 13-DMT, and 15-DMT in cord blood did not differ from that in fetal venous blood. Zheng et al ${ }^{59}$ observed no difference in the primary Tac metabolite concentrations between the arterial and venous umbilical cord blood.

At several days after birth, Tac concentrations were found to decline rapidly, indicating the ability of a newborn infant to clear Tac after birth. ${ }^{47}$ At 1 year after birth, CYP3A4 activity increases rapidly and can reach $120 \%$ of adult CYP3A4 activity. ${ }^{63}$ Bramham et $\mathrm{al}^{57}$ also found undetectable Tac concentrations in bottle-fed infants after 8 and 20 days, in whom Tac concentrations declined by approximately $15 \%$ per day owing to metabolism in the infant. This is likely caused by downregulation of CYP3A7 expression and upregulation of CYP3A4 expression shortly after birth. ${ }^{62}$ Finally, Jain et $\mathrm{al}^{47}$ reported higher Tac concentrations at delivery in infants with low birth weight (LBW), suggesting a slower metabolism in preterm or LBW infants. Those infants might need monitoring of Tac concentrations after birth. 


\section{Teratogenicity \\ Immunological Outcomes}

Theoretically, neonatal exposure to Tac could affect the development of the immune system. To examine this effect, Ono et $\mathrm{al}^{66}$ studied 28 children born to female kidney transplant recipients at birth and after 8 months and compared these children with 40 children born to healthy, nonimmunosuppressed mothers. The kidney transplant recipients used a CNI (70\% Tac and 30\% CsA), AZA, and prednisone during gestation. Children of mothers under immunosuppressive therapy had significantly lower numbers of white blood cells, neutrophils, and eosinophils than those of the controls at time of birth. Eighty percent of the children had low B-cell numbers, $15 \%$ had low $\mathrm{CD}^{+}$T-cell numbers, and $15 \%$ had low $\mathrm{CD}^{+} \mathrm{T}$-cell numbers at birth. After 8 months, lymphocyte counts had normalized in most children, and B-cell numbers were higher than those in the control group. ${ }^{66}$ DrozdowskaSzymczak et al observed no significant differences in immunoglobulin concentrations at birth between infants born to mothers on Tac treatment after SOT and those born to healthy mothers. ${ }^{67,68}$ Kociszewska-Najman et al ${ }^{69}$ reported that white blood cell counts within the first 72 hours after birth were within the normal limits.

In addition to decreased lymphocyte counts, $28.6 \%$ of the children born to mothers on immunosuppressive treatment experienced infections necessitating hospitalization during a follow-up time of 12 months after birth, whereas this incidence was only $7.5 \%$ in the control group. ${ }^{66}$ Compared with another cohort consisting of 28 children born to healthy mothers (the children were matched for gender, gestational age, and birth weight), children of mothers on immunosuppressive treatment had a higher chance of hospitalization due to infectious diseases $(28.6 \%$ versus $3.6 \%$; odds ratio, 4.351 , $95 \%$ confidence interval 1.026-18.448). KociszewskaNajman et al did not find a significant difference in the incidence of congenital infections between children born to SOT recipients $(21.1 \%)$ and those born to healthy mothers $(13.0 \%)$, despite higher rates of prematurity in children born to transplant recipients. The rates of infections also did not differ significantly between Tac plus corticosteroid treatment (23.9\%), CsA plus corticosteroid treatment (13.6\%), and AZA plus corticosteroid and CNI treatment (26.9\%). ${ }^{69}$

\section{Pregnancy Outcomes}

In animals, Tac treatment has been associated with decreased numbers of live births, increased incidence of fetal malformations, LBW, and maternal toxicity. ${ }^{24,70}$ These adverse pregnancy outcomes are dose-dependent. ${ }^{70}$

Despite the fact that Tac enters the fetal circulation, no association between Tac and congenital malformations has been described in humans. ${ }^{6,71,72}$ The incidence of fetal malformations in children born to mothers after SOT, the majority of whom were exposed to Tac during gestation, is reported to range between $0 \%$ and $11.8 \%$ of live births. ${ }^{4,6,48,73-80}$ No specific pattern of malformations was recognized. This incidence is similar to the rate of fetal malformations in the general population, which is estimated to be $3 \%$. In addition, a similar incidence of fetal malformations, ranging between
$4 \%$ and $5 \%$, was reported by the National Transplantation Pregnancy Registry (NTPR) for SOT recipient mothers, irrespective of their immunosuppressive treatment. ${ }^{10,71,81}$

However, both cohort studies and studies using data from the NTPR in SOT recipients on CNI treatment during pregnancy (see Table S2, Supplemental Digital Content 2, http://links.lww.com/TDM/A406, which shows pregnancy outcomes) reported a high incidence of preterm delivery $(<37$ weeks), LBW, and small for gestational age (SGA) infants. ${ }^{4-6,9,36,47,48,50,73-75,77-80,82-100}$ In summary, among infants exposed to CNIs during pregnancy, 6.1\%-73.1\% were born preterm, $18.9 \%-67 \%$ had LBW, and $8.5 \%-40.7 \%$ were SGA (see Table S2, Supplemental Digital Content 2, http:// links.lww.com/TDM/A406). Of note, most studies did not correct birth weight for the effect of preterm delivery. Yuksel et al ${ }^{89}$ did not find associations between the mothers' blood Tac concentrations in the first trimester and the incidence of LBW, prematurity, and other pregnancy complications.

The higher risk for LBW and preterm delivery can be explained by the higher incidence of pregnancy-related hypertension and preeclampsia, which are reported to range between $3.1 \%-58 \%$ and $3.1 \%-61.5 \%$, respectively. $4,36,48,73-$ $76,78-80,82-86,88,90-94,101,102$ This may, in turn, be explained by the vasoconstrictive effects of CNIs via increased release of vasoconstrictive agents, decreased production of vasodilatory agents, and retention of sodium and water. ${ }^{10,103-108}$ The risk of adverse pregnancy outcomes appears to be independent of the type of CNI used. ${ }^{78,92}$ However, the LBW and preterm delivery may also be explained by other factors, such as weakening of the connective tissue due to long-term steroid use. Overall, preterm delivery is found in $45 \%-60 \%$ of all pregnancies among renal transplant recipients. ${ }^{109}$ Dinelli et al, ${ }^{93}$ followed infants born to transplant recipient mothers under immunosuppressive treatment postpartum and compared them with healthy children born at term with normal weight for gestational age. At the age of 6 months, the 2 groups had a similar weight for age, and at the age of 12 months, the 2 groups had a similar length for age, despite the higher incidence of premature births and SGA.

As Tac is nephrotoxic, it can be postulated that Tac injures the infant's kidneys. Although renal dysfunction and high serum creatinine concentrations have been reported in infants exposed to Tac during pregnancy, ${ }^{6,47}$ there are insufficient data to support that this was caused by Tac treatment. Tac use during pregnancy has also been associated with transient perinatal hyperkalemia in the infant. ${ }^{6,47,110-112}$ This hyperkalemia was, however, resolved spontaneously within 2448 hours ${ }^{47,112}$ At present, it is unclear if the risk of hyperkalemia is increased in children born to mothers treated with Tac compared with that in those born to mothers not treated with Tac.

Prenatal exposure to Tac may also be related to childhood obesity. Schreiber-Zamor et al found a 2.8-fold higher body mass index in children of mothers who received Tac treatment. However, the higher body mass index was found not to be correlated with LBW. ${ }^{113}$

The clinical outcomes of pregnancies born to fathers who were on Tac at the time of conception were described by 
Armenti et al. Ninety-seven male kidney transplant recipients receiving CsA, Tac, MMF, sirolimus, or a combination of these drugs were included in their study. These kidney transplant recipients fathered a total of 126 children. The mean gestational age ( $39 \pm 2.4$ weeks) and the mean birth weight $(3244 \pm 649 \mathrm{~g})$ were similar to those in the general population. ${ }^{79,114}$

\section{Breastfeeding}

Tac is excreted in small amounts into human breast milk (Table 2). Tac concentrations in breast milk were reported to range between 0.0038 and $3.219 \mathrm{ng} /$ $\mathrm{mL} .{ }^{47,57,59,65,115-117}$ Milk-to-whole-blood and milk-toplasma ratios were $0.08-0.23^{115,116}$ and $0.12-0.5,47,59,117$ respectively. Zheng et al investigated Tac excretion into breast milk over a 12-hour steady-state dosing interval in one patient. The highest maternal blood and plasma Tac concentrations were observed at 1 hour after Tac administration, and the highest Tac concentration in breast milk was observed after 6 hours $(1.11 \mathrm{ng} / \mathrm{mL})$. This resulted in milk-to-blood and milk-to-plasma AUC ratios of 0.13 and 2.89, respectively. Unbound Tac constituted $2.7 \pm 0.4 \%(n=3)$ of Tac observed in the mothers' plasma and $3.7 \pm 0.6 \%(n=3)$ of Tac found in breast milk. The ratio of unbound Tac in the milk-toplasma AUC ratio was 3.96. ${ }^{59}$

The estimated daily Tac ingestion by infants via breast milk ranged between $0.059 \%$ and $0.9 \%$ of the mother's weight-adjusted dose, assuming a daily intake of $150 \mathrm{~mL}$ of milk per kilogram. ${ }^{47,57,59,65,115-117}$ Based on the highest measured Tac concentration in breast milk $\left(3.219 \mathrm{ng} / \mathrm{mL}^{65}\right)$ and the assumption that an infant consumes $150 \mathrm{~mL} / \mathrm{kg}$ milk per day, the maximum ingested dose would be $0.00048 \mathrm{mg} / \mathrm{kg}$ per day, which is far lower than the lowest recommended intake for pediatric SOT recipients $(0.15 \mathrm{mg} / \mathrm{kg}$ per day $){ }^{65}$ Kociszewska-Najman et $\mathrm{al}^{65}$ estimated the average ingestion of the 13-DMT and 15-DMT metabolites to be 0.02 and 0.01 $\mathrm{mcg} / \mathrm{kg}$ per day. Moreover, Zheng et $\mathrm{a}^{59}$ observed a mean 13-DMT concentration in the breast milk of $0.03 \mathrm{ng} / \mathrm{mL}$, whereas the concentrations of Tac metabolites 15-DMT, 31DMT, and 12-HT were under the limit of detection.

Breastfed children were able to eliminate Tac to undetectable concentrations over time. ${ }^{47,57,117,118}$ Bramham et al observed a decline in Tac concentrations of approximately $15 \%$ per day in both breastfed and bottle-fed infants. In addition, they did not find a significant difference in Tac concentration between breastfed and bottle-fed infants

TABLE 2. Breastfeeding During Tac Treatment

\begin{tabular}{|c|c|c|c|c|}
\hline Article, Year & $\begin{array}{c}N \text { (Infants With } \\
\text { Breast Milk Sample) }\end{array}$ & $\begin{array}{l}\text { Tac Dose Administered } \\
\text { to the Mother }\end{array}$ & $\begin{array}{c}\text { Breast Milk } \\
\text { Concentration (mcg/L) }\end{array}$ & $\begin{array}{c}\text { Estimated Infant } \\
\text { Ingestion }(\mathrm{mcg} / \mathrm{kg} / \mathrm{d})\end{array}$ \\
\hline French et al, $2003^{115}$ & 1 & $0.1 \mathrm{mg} / \mathrm{kg} / \mathrm{d}$ & 0.429 & 0.06 \\
\hline Jain et al, $1997^{47}$ & 6 & & $0.3-1.9 \dagger$ & $0.045-0.29$ \\
\hline Kociszewska-Najman et al, $2018^{65}$ & 14 & $5-10 \mathrm{mg}$ twice daily & $3.219 \dagger$ (peak) & 0.1514 \\
\hline Zheng et al, $2013^{59}$ & 1 & $3.0 \mathrm{mg} / \mathrm{d}$ & 0.93 & 0.14 \\
\hline Gouraud et al, $2012^{118}$ & 6 & $4.5-15 \mathrm{mg} / \mathrm{d}$ & N.A. & N.A. \\
\hline Izumi et al, $2014^{119}$ & 2 & $3.0 \mathrm{mg} / \mathrm{d}$ & N.A. & N.A. \\
\hline
\end{tabular}

\begin{tabular}{|c|c|c|c|c|}
\hline Article, Year & $\begin{array}{c}\text { Estimated Infant Ingestion } \\
\text { (\% of Weight Adjusted } \\
\text { Maternal Dose)* }\end{array}$ & $\begin{array}{c}\text { Infant Blood } \\
\text { Concentration }(\mathrm{mcg} / \mathrm{L})\end{array}$ & Milk:blood Ratio & Milk:plasma Ratio \\
\hline Bramham et al, $2013^{57}$ & $0.23 \%$ & N.A. & N.A. & N.A. \\
\hline & & & Postdose: 0.09 & \\
\hline Gardiner and Begg et al, $2006^{116}$ & $0.5 \%$ & N.A. & 0.23 & N.A. \\
\hline Jain et al, $1997^{47}$ & $<0.2 \%$ & N.A. & N.A. & 0.5 \\
\hline & & & & Unbound Tac AUC ratio: 3.96 \\
\hline Hiramatsu et al, $2018^{117}$ & $0.18 \%$ & N.A. & N.A. & 0.12 \\
\hline Gouraud et al, $2012^{118}$ & N.A. & $<1.9$ & N.A. & N.A. \\
\hline Izumi et al, $2014^{119}$ & N.A. & $0.2-0.5 \ddagger$ & N.A. & N.A. \\
\hline
\end{tabular}

*Assuming infant milk ingestion of $150 \mathrm{~mL} / \mathrm{kg}$ per day for an average 3-month-old child.

†Colostrum.

One hour after breastfeeding.

AUC, area under the plasma concentration-time curve; N.A., not applicable. 
(median, $1.3 \mathrm{mg} / \mathrm{L}$; range, $0.0-4.0$ versus $1.0 \mathrm{mg} / \mathrm{L}$; range, $0.0-2.3$; respectively; $P=0.91)$. The authors concluded that the detectable Tac concentrations in these infants after birth were caused by previous placental transfer, rather than ingestion via breast milk. ${ }^{57}$

Theoretically, Tac may cause immunological or nephrotoxic side effects in infants. However, no studies have described any adverse outcomes in children breastfed by mothers under Tac treatment within follow-up periods of 230 months. ${ }^{66,115,118-121}$

Taken together, infants will ingest small amounts of Tac via the breast milk of mothers under Tac treatment, but no adverse outcomes related to Tac ingestion via breast milk have been reported. The benefits of breastfeeding may therefore outweigh the theoretical risks of Tac ingestion for infants.

\section{MYCOPHENOLIC ACID}

MPA inhibits inosine monophosphate dehydrogenase, leading to inhibition of purine synthesis and inhibition of T-and B-cell proliferation. ${ }^{122}$ MPA can be administered as the prodrug MMF or as enteric-coated mycophenolate sodium, both of which are converted into MPA.

MPA is often administered to SOT recipients in combination with Tac. However, in 2007, the United States Food and Drug Administration (FDA) changed the pregnancy safety category of MMF from " $\mathrm{C}$ " to "D," meaning that "There is positive evidence of human fetal risk, but potential benefits may warrant use of the drug in pregnant women despite potential risks." 123 Women under MPA treatment should therefore stop MPA administration or switch to an alternative immunosuppressive agent when considering conception. ${ }^{123,124}$ In addition, concerns have emerged about the safety of MPA usage in male allograft recipients during conception.

\section{Fertility}

In male rats, MPA treatment at a dose of $20 \mathrm{mg} / \mathrm{kg}$ per day, which corresponds to 2-3 times the therapeutic systemic exposure in human renal allograft recipients, did not affect fertility. ${ }^{123,125}$ To the best of our knowledge, there are currently no data on the effect of MPA on human male fertility.

In female rats, MPA treatment at a dose of $4.5 \mathrm{mg} / \mathrm{kg}$ per day, which corresponds to approximately half the therapeutic exposure in female renal allograft recipients, did not affect fertility. ${ }^{123,125}$ Among women with systemic lupus erythematosus, anti-Müllerian hormone concentrations were comparable between those exposed and not exposed to MPA. ${ }^{126}$ In addition, in a retrospective cohort study including 35 women who wished to become pregnant, predictors for pregnancy were analyzed, and regression analysis results showed that the use of Tac and MMF (compared with other immunosuppressive drug regimens) was a positive predictor of pregnancy within 1 year in women trying to conceive, along with regular menstrual cycles after transplantation and age at transplantation. ${ }^{34}$
Nevertheless, although insufficient evidence is available on the effect of MPA treatment on fertility, there is no evidence of impaired fertility in both men and women.

\section{Teratogenicity \\ Teratogenicity of MPA Use in Women}

In vitro tests in rat whole-embryo cultures showed the embryotoxic potential of MPA. Exposure of rat embryos to MPA resulted in dysmorphogenic development at low MPA concentrations and malformations at high MPA concentrations. ${ }^{127,128}$ The teratogenic effects of MPA were also observed in zebrafish and rabbit embryos. ${ }^{129}$

Data from pregnancy registries and 38 case reports (see Table S3, Supplemental Digital Content 3, http://links.lww. com/TDM/A406 which presents pregnancy outcomes) showed an increased risk of spontaneous abortion, congenital malformations, and other adverse fetal outcomes in women under MPA treatment during conception or pregnancy. ${ }^{80,90,98,130-154}$ From these data, a pattern of malformations was recognized, including orofacial clefts (cleft lip and palate), ear malformations (microtia and atresia of the external auditory canals), micrognathia, and eye defects (coloboma and hypertelorism). Other abnormalities that have been reported, albeit with lower frequencies, are limb abnormalities, congenital heart defects, esophageal atresia, diaphragmatic hernia, vertebral defects, and kidney abnormalities. ${ }^{155,156}$

The exact frequencies of miscarriages and congenital malformations are still unclear owing to small patient numbers and potential selection biases in voluntary registries. In women exposed to MPA during conception or pregnancy, a spontaneous abortion rate of $40 \%-52 \%$ was reported. ${ }^{80,130-}$ 132 The rate of congenital malformations was estimated to be $23 \%-27 \%$. This rate constitutes $4 \%-5 \%$ of live births in SOT recipients using other immunosuppressive agents. ${ }^{125}$

Constantinescu et $\mathrm{al}^{157}$ studied data from the NTPR and analyzed the outcomes of 444 pregnancies in renal allograft recipients. They concluded that discontinuation of MPA treatment before conception resulted in a higher rate of live births $(78 \%$ versus $48 \%)$ and a lower rate of miscarriages $(20 \%$ versus $48 \%$ ) than those in renal allograft recipients exposed to MPA in the early pregnancy period. The rate of birth defects in the group that discontinued MPA treatment were similar to that in the general population. King et $\mathrm{al}^{158}$ analyzed the outcomes of 382 pregnancies reported in the NTPR. They observed an increased risk of miscarriages and birth defects following discontinuation of MPA in the second trimester or later. In contrast to the previous studies, Ghafari and Sanadgol ${ }^{159}$ did not find any differences in perinatal outcomes between pregnant women exposed to MPA versus AZA.

\section{Teratogenicity of MPA Use in Men}

In recent years, concerns about the safety of MPA use in men during conception have emerged. Therefore, the European Medicines Agency recommended the following: "sexually active men taking mycophenolate are recommended to use condom for sex during treatment and for 90 days thereafter; partners of childbearing potential are also 
recommended to use highly effective contraception for the same period."160,161 However, the current evidence does not support this recommendation.

In 2015, Morken et $\mathrm{al}^{162}$ conducted a national population-based cohort study analyzing 474 pregnancies fathered by male transplant recipients in Norway. Data were collected from the Medical Birth Registry of Norway and the Norwegian Transplant Registry. They found a higher risk for preeclampsia in pregnancies fathered by men after SOT than in pregnancies fathered by men before SOT (adjusted odds ratio, 7.4; 95\%-confidence interval 1.1-51.4). No significant differences in preeclampsia, major birth defects, preterm deliveries, and SGA were found between the outcomes of pregnancies fathered by SOT recipients and pregnancy outcomes in the general population of Norway. The most common immunosuppressive therapy was a combination of a CNI, glucocorticoids, and AZA or MPA. However, the exact number of patients on MPA treatment was not specified.

Recent studies compared the outcomes of pregnancies fathered by allograft recipients receiving MPA at the time of conception with pregnancy outcomes in the general population or outcomes of pregnancies fathered by SOT recipients not exposed to MPA. Jones et $\mathrm{al}^{163}$ analyzed data of 152 male transplant recipients under MPA treatment during conception from the NTPR. Out of 205 pregnancies, 194 (94\%) were live births. Prematurity ( $<37$ weeks of gestation) occurred in 21 pregnancies $(10.8 \%), 8$ children $(4.1 \%)$ had a birth weight of $<2500 \mathrm{~g}$, and 6 cases $(3.1 \%)$ showed birth defects. These birth defects included a club foot, ankyloglossia, PraderWilli syndrome, pyloric stenosis, congenital diaphragmatic hernia (incompatible with life), and ventricular septal defect. All percentages were comparable to those in the general population in the United States.

Midtvedt et al ${ }^{160}$ conducted a national population-based cohort study, analyzing outcomes of pregnancies $(n=350)$ fathered by renal transplant recipients $(n=230)$ in Norway. Data were collected from the Medical Birth Registry of Norway and the Norwegian Transplant Registry. The results revealed 155 pregnancies fathered by men exposed to MPA during conception and 195 pregnancies fathered by men not exposed to MPA. Malformations occurred in 3.9\% of pregnancies in the exposed group versus $2.6 \%$ in the unexposed group, which was not significantly different. Moreover, no significant difference was found in gestational age or birth weight between the pregnancy outcomes of the groups exposed and unexposed to MPA. Finally, 2 smaller retrospective studies in male transplant recipients also reported no association between MPA treatment and the risk of birth defects. ${ }^{164,165}$ These results suggest that exposure of male SOT recipients to MPA at the time of conception does not affect pregnancy outcomes.

\section{Pharmacokinetics}

Because there is a strong recommendation against prescription of MPA to women who are trying to conceive (see previous paragraph 3.2.2.), there are very limited data on the pharmacokinetics of MPA during pregnancy. In a newborn whose mother used MMF during pregnancy as immunosuppressive treatment after renal transplantation, an MMF plasma concentration of $3.1 \mathrm{mg} / \mathrm{L}$ was reported; however, at 10 days after birth, the MMF plasma concentration decreased to $<0.6$ $\mathrm{mg} / \mathrm{L} .{ }^{148}$ This supports the theory that MPA is able to cross the placental barrier and enter the fetal circulation.

\section{Breastfeeding}

There is insufficient evidence to provide a recommendation regarding MPA use during breastfeeding. In rats, MPA was excreted into breast milk. ${ }^{123}$ However, no pharmacological studies have investigated the presence of MPA in human breast milk. In the NTPR, breastfeeding by a transplant recipient on MPA treatment was reported only for 7 newborns, and no adverse events associated with breastfeeding were reported in these newborns. ${ }^{166,167}$

\section{DISCUSSION, GAP ANALYSIS, AND OUTLOOK}

Conception, pregnancy, and parenthood following SOT are realistic options. Transplant professionals will encounter patients who consider conception or pregnancy, and these patients will most likely be treated with Tac plus MPA combination therapy at the time of counseling.

MPA is teratogenic, and thus, its use during conception and (early) pregnancy is strongly discouraged. For women under treatment with MPA, switching to AZA or an immunosuppressive regimen without MPA is strongly recommended. Breastfeeding during MPA treatment cannot be considered safe owing to the lack of evidence.

Recent concerns about the safety of MPA use in men during conception led to the European Medicines Agency recommendation of contraception use until at least 90 days after discontinuation of MPA treatment. However, the current evidence does not support this recommendation. Both large, population-based cohort studies ${ }^{160,163}$ using data of national birth and transplantation registries, as well as smaller retrospective studies, ${ }^{164,165}$ did not find significant differences in pregnancy outcomes and the risk of congenital malformations between men using MPA and those not using MPA at the time of conception. These results suggest that it is not necessary for men to use contraception while on MPA treatment or to switch to an alternative immunosuppressive agent. In addition, switching to an MPA-free immunosuppressive regimen may be associated with an increased rejection risk. The Dutch Transplant Society has issued a guidance document that recommends continuation of MPA treatment after providing information about the scarcity of evidence for the current warning to male transplant patients with a wish to conceive. ${ }^{168}$ To collect more evidence, the transplant community is encouraged to actively report live births from male SOT recipients receiving immunosuppressive drugs. ${ }^{169}$

Tac may negatively affect both male and female fertility. However, data are limited, and because fertility is strongly affected by renal function, Tac may be the safest option for SOT recipients wishing to become a parent.

Continuation of Tac treatment during pregnancy is reasonable. Tac enters the fetal circulation, but this does not appear to result in a higher risk of congenital malformation than that in the general population. In the mother, Tac seems to be associated with an increased risk of pregnancy-related 
hypertension and preeclampsia compared with CNI-free immunosuppressive regimens. These side effects are likely mediated by the vasoconstrictive effects of Tac and may in turn explain the higher incidence of LBW, preterm birth, and SGA. Despite this, continuation of Tac during pregnancy seems to be the best treatment option. No alternative immunosuppressive regimen has been shown to be a better option in terms of offering a better balance between adequate immunosuppression and adverse outcomes for mother and child. Data on other immunosuppressive agents during pregnancy are scarce. ${ }^{170}$

\section{Implications for TDM}

Little to no data are available on MPA pharmacokinetics during pregnancy and breastfeeding in both mother and child, and therefore, no evidence-based recommendations regarding TDM of MPA for these specific clinical situations can be made.

Tac has a narrow therapeutic index and its adverse effects during pregnancy in animals appear to be dose dependent. Close maintenance of women in the Tac target exposure range during pregnancy is therefore of utmost importance.

Pregnancy causes alterations in the pharmacokinetics of Tac. CYP3A expression is increased, resulting in increased Tac (first-pass) metabolism. The volume of distribution of Tac also increases (owing to changes in the hematocrit and plasma protein concentrations), resulting in a decrease in whole-blood Tac concentration but also in an increased unbound Tac-to-total Tac concentration ratio. During normal pregnancy, the mother does not develop an immune response toward the fetus. It has been hypothesized that pregnancyinduced hyporesponsiveness of the mother's immune system might also lead to tolerance toward the allograft, allowing reduction of immunosuppressive therapy. However, immunological changes during pregnancy are complex, and it is unclear whether pregnancy decreases or increases the risk for alloimmune responses and rejection. ${ }^{171-173}$ To the best of our knowledge, only one case of allograft tolerance following pregnancy has been reported. In this case, all immunosuppressive therapy could be stopped during pregnancy in a mother who had received a renal transplant 9 years previously. ${ }^{174}$ Although no increased rejection incidence has been reported in patients without dose adjustments, ${ }^{5,6}$ owing to low whole-blood Tac concentrations, it is recommended to increase the daily Tac dose by $20 \%-45 \%$ to maintain the target predose concentrations. ${ }^{49,50}$ However, how this strategy affects the unbound Tac concentrations is unclear, although they are likely to increase relative to the total Tac concentrations. As unbound Tac is considered a part of the drug, which is able to bind to the receptor, unbound Tac concentrations may correlate better with drug efficacy compared with whole-blood Tac concentrations. Monitoring of unbound Tac during pregnancy seems to be reasonable, especially when toxicity occurs or in women with anemia and/or hypoalbuminemia. ${ }^{37,39}$ However, no unbound Tac target concentrations have been defined.

Because the optimal concentration of unbound Tac is unclear, measurement of unbound Tac is unavailable in many laboratories, and in clinical practice, whole-blood Tac concentrations are measured, it may be safer to increase the Tac dose and accept higher unbound Tac concentrations. Considering the changes in pharmacokinetics during pregnancy, one may expect changes in Tac concentrations at the target site, which in turn can affect clinical outcomes. Tac concentration in lymphocytes could be an appropriate matrix to monitor Tac treatment. ${ }^{175-178}$ In a study by Capron et al, 179 intracellular Tac concentration was correlated with both the development and severity of rejection after liver transplantation. However, the authors of this review think that at present, there is insufficient evidence to make recommendations regarding the optimal matrix for TDM of Tac during pregnancy. More research is necessary on the effects of pregnancy on unbound and intracellular Tac concentrations, as well as their effect on clinical outcomes.

During breastfeeding, infants will ingest very low amounts of Tac, which are estimated to range between $0.059 \%$ and $0.9 \%$ of the mother's weight-adjusted daily dose. ${ }^{65}$ No Tac-related adverse events have been reported in breastfed children, and thus, Tac treatment is considered not an absolute contraindication for breastfeeding. Moreover, TDM of the infant is unlikely to improve patient care.

\section{CONCLUSION}

Taken together, Tac treatment during conception, pregnancy, and lactation seems to be relatively safe in terms of the health of the mother (unborn) child, and allograft. However, more evidence is needed to make recommendations on both Tac dose adjustments and alternative matrices to whole-blood for TDM of Tac during pregnancy. As MPA is teratogenic, it is strongly recommended that women who are trying to conceive switch from MPA to AZA. MPA treatment in men during conception seemsto have no adverse effect on pregnancy outcomes.

\section{ACKNOWLEDGMENTS}

The authors thank biomedical information specialist Elise Krabbendam of the Medical Library of the Erasmus MC for assisting with the creation of the search terms.

\section{REFERENCES}

1. Murray JE, Reid DE, Harrison JH, et al. Successful pregnancies after human renal transplantation. N Engl J Med. 1963;269:341-343.

2. Cabiddu G, Spotti D, Gernone G, et al. A best-practice position statement on pregnancy after kidney transplantation: focusing on the unsolved questions. The Kidney and Pregnancy Study Group of the Italian Society of Nephrology. J Nephrol. 2018;31:665-681.

3. Shah S, Verma P. Overview of pregnancy in renal transplant patients review. Int J Nephrol. 2016;2016:4539342.

4. Jain AB, Reyes J, Marcos A, et al. Pregnancy after liver transplantation with tacrolimus immunosuppression: a single center's experience update at 13 years. Transplantation. 2003;76:827-832.

5. Jain AB, Shapiro R, Scantlebury VP, et al. Pregnancy after kidney and kidney-pancreas transplantation under tacrolimus: a single center's experience. Transplantation. 2004;77:897-902.

6. Kainz A, Harabacz I, Cowlrick IS, et al. Review of the course and outcome of 100 pregnancies in 84 women treated with tacrolimus. Transplantation. 2000;70:1718-1721. 
7. Gutiérrez MJ, Acebedo-Ribó M, García-Donaire JA, et al. Pregnancy in renal transplant recipients. Transpl Proc. 2005;37:3721-3722.

8. Scott LJ, McKeage K, Keam SJ, et al. Tacrolimus. Drugs. 2003;63: 1247-1297.

9. Costa MLB, Surita FGC, Passini R Jr, et al. Pregnancy outcome in female liver transplant recipients. Transpl Proc. 2011;43:1337-1339.

10. McKay DB, Josephson MA. Pregnancy in recipients of solid organseffects on mother and child. N Engl J Med. 2006;354:1281-1293.

11. Georgiou GK, Dounousi E, Harissis HV. Calcineurin inhibitors and male fertility after renal transplantation-a review. Andrologia. 2016; 48:483-490.

12. Josephson MA, McKay DB. Pregnancy in the renal transplant recipient. Obstet Gynecol Clin North Am. 2010;37:211-222.

13. Brunet M, van Gelder T, Asberg A, et al. Therapeutic drug monitoring of tacrolimus-personalized therapy: second consensus report. Ther Drug Monit. 2019;41:261-307.

14. Bramer WM, Milic J, Mast F. Reviewing retrieved references for inclusion in systematic reviews using EndNote. J Med Libr Assoc. 2017;105: 84-87.

15. Wang GC, Zheng JH, Xu LG, et al. Measurements of serum pituitarygonadal hormones and investigation of sexual and reproductive functions in kidney transplant recipients. Int J Nephrol. 2010;2010:612126.

16. Saha MT, Saha HH, Niskanen LK, et al. Time course of serum prolactin and sex hormones following successful renal transplantation. Nephron. 2002:92:735-737.

17. Akbari F, Alavi M, Esteghamati A, et al. Effect of renal transplantation on sperm quality and sex hormone levels. BJU Int. 2003;92:281-283.

18. Kantarci G, Sahin S, Uras AR, et al. Effects of different calcineurin inhibitors on sex hormone levels in transplanted male patients. Transpl Proc. 2004;36:178-179.

19. Tainio J, Jahnukainen K, Nurmio M, et al. Testicular function, semen quality, and fertility in young men after renal transplantation during childhood or adolescence. Transplantation. 2014;98:987-993.

20. Miyata H, Satouh Y, Mashiko D, et al. Sperm calcineurin inhibition prevents mouse fertility with implications for male contraceptive. Science. 2015;350:442-445.

21. Hisatomi A, Fujihira S, Fujimoto Y, et al. Effect of Prograf (FK506) on spermatogenesis in rats. Toxicology. 1996;109:75-83.

22. Caneguim BH, Cerri PS, Spolidorio LC, et al. Structural alterations in the seminiferous tubules of rats treated with immunosuppressor tacrolimus. Reprod Biol Endocrinol. 2009;7:19.

23. Caneguim BH, Cerri PS, Spolidorio LC, et al. Immunosuppressant prograf (tacrolimus) induces histopathological disorders in the peritubular tissue of rat testes. Cells Tissues Organs. 2011;194:421-430.

24. FDA. Drugs: FDA Approved Drug Products U.S. Food and Drug Administration Web Site. 2018. Available at: https://www.accessdata. fda.gov/drugsatfda docs/label/2019/ 050708s 050,050709 s042,210115s002lbl.pdf. Accessed November 27, 2019.

25. Tai J, Tze WJ, Murase N, et al. Effect of FK506 on rat Leydig cell function-in vivo and in vitro study. Metabolism. 1994;43:533-537.

26. Tauchmanova L, Carrano R, Sabbatini M, et al. Hypothalamic-pituitarygonadal axis function after successful kidney transplantation in men and women. Hum Reprod. 2004;19:867-873.

27. Tondolo V, Citterio F, Panocchia N, et al. Gonadal function and immunosuppressive therapy after renal transplantation. Transpl Proc. 2005; 37:1915-1917.

28. Framarino-dei-Malatesta M, Derme M, Manzia TM, et al. Impact of mTOR-I on fertility and pregnancy: state of the art and review of the literature. Expert Rev Clin Immunol. 2013;9:781-789.

29. Huyghe E, Zairi A, Nohra J, et al. Gonadal impact of target of rapamycin inhibitors (sirolimus and everolimus) in male patients: an overview. Transpl Int. 2007;20:305-311.

30. Josephson MA, McKay DB. Women and transplantation: fertility, sexuality, pregnancy, contraception. Adv Chron Kidney Dis. 2013;20:433440

31. Lessan-Pezeshki M, Ghazizadeh S, Khatami MR, et al. Fertility and contraceptive issues after kidney transplantation in women. Transpl Proc. 2004;36:1405-1406.

32. Datta J, Palmer MJ, Tanton C, et al. Prevalence of infertility and help seeking among 15000 women and men. Hum Reprod. 2016;31:21082118 .
33. Karayalcin R, Genc V, Oztuna D, et al. Gynecologic symptoms and sexual function in female kidney allograft recipients. Transpl Proc. 2010;42:2551-2555.

34. Yaprak M, Dogru V, Sanhal CY, et al. Fertility outcome after renal transplantation: a single-center experience. Transpl Proc. 2019;51: $1108-1111$

35. te Velde ER, Eijkemans R, Habbema HD. Variation in couple fecundity and time to pregnancy, an essential concept in human reproduction. Lancet. 2000;355:1928-1929.

36. Kennedy C, Hussein W, Spencer S, et al. Reproductive health in Irish female renal transplant recipients. Ir J Med Sci. 2012;181: 59-63.

37. Vanhove T, Annaert P, Kuypers DRJ. Clinical determinants of calcineurin inhibitor disposition: a mechanistic review. Drug Metab Rev. 2016;48:88-112.

38. Hebert MF, Easterling TR, Kirby B, et al. Effects of pregnancy on CYP3A and P-glycoprotein activities as measured by disposition of midazolam and digoxin: a University of Washington specialized center of research study. Clin Pharmacol Ther. 2008;84:248-253.

39. Hebert MF, Zheng S, Hays K, et al. Interpreting tacrolimus concentrations during pregnancy and postpartum. Transplantation. 2013;95:908915

40. Zheng SM, Easterling TR, Umans JG, et al. Pharmacokinetics of tacrolimus during pregnancy. Ther Drug Monit. 2012;34:660-670.

41. Casale JP, Doligalski CT. Pharmacologic considerations for solid organ transplant recipients who become pregnant. Pharmacotherapy. 2016; 36:971-982.

42. Hytten F. Blood volume changes in normal pregnancy. Clin Haematol. 1985; 14:601-612.

43. Aweeka FT, Stek A, Best BM, et al. Lopinavir protein binding in HIV1-infected pregnant women. HIV Med. 2010;11:232-238.

44. Anderson GD. Pregnancy-induced changes in pharmacokinetics: a mechanistic-based approach. Clin Pharmacokinet. 2005;44:9891008.

45. Andrews LM, Li Y, De Winter BCM, et al. Pharmacokinetic considerations related to therapeutic drug monitoring of tacrolimus in kidney transplant patients. Expert Opin Drug Metab Toxicol. 2017;13:12251236.

46. Tracy TS, Venkataramanan R, Glover DD, et al. Temporal changes in drug metabolism (CYP1A2, CYP2D6 and CYP3A Activity) during pregnancy. Am J Obstet Gynecol. 2005;192:633-639.

47. Jain A, Venkataramanan R, Fung JJ, et al. Pregnancy after liver transplantation under tacrolimus. Transplantation. 1997;64:559-565.

48. Aktürk S, Çelebi ZK, Erdoğmuş Ş, et al. Pregnancy after kidney transplantation: outcomes, tacrolimus doses, and trough Levels. Transpl Proc. 2015;47:1442-1444.

49. Bhagra CJ, Bhagra SK, Donado A, et al. Pregnancy in cardiac transplant recipients. Clin Transpl. 2016;30:1059-1065.

50. Kim H, Jeong JC, Yang J, et al. The optimal therapy of calcineurin inhibitors for pregnancy in kidney transplantation. Clin Transpl. 2015; 29:142-148

51. Chapman AB, Abraham WT, Zamudio S, et al. Temporal relationships between hormonal and hemodynamic changes in early human pregnancy. Kidney Int. 1998;54:2056-2063.

52. Sturgiss SN, Dunlop W, Davison JM. Renal haemodynamics and tubular function in human pregnancy. Baillieres Clin Obstet Gynaecol. 1994;8:209-234.

53. Antza C, Cifkova R, Kotsis V. Hypertensive complications of pregnancy: a clinical overview. Metabolism. 2018;86:102-111.

54. Zhu Y, Zhang C. Prevalence of gestational diabetes and risk of progression to type 2 diabetes: a global perspective. Curr Diab Rep. 2016; $16: 7$

55. Freriksen JJM, Feyaerts D, van den Broek PHH, et al. Placental disposition of the immunosuppressive drug tacrolimus in renal transplant recipients and in ex vivo perfused placental tissue. Eur J Pharm Sci. 2018;119:244-248

56. Fuchs KM, Coustan DR. Immunosuppressant therapy in pregnant organ transplant recipients. Semin Perinatol. 2007;31:363-371.

57. Bramham K, Chusney G, Lee J. Breastfeeding and tacrolimus: serial monitoring in breast-fed and bottle-fed infants. Clin J Am Soc Nephrol. 2013;8:563-567. 
58. Han LW, Gao C, Mao Q. An update on expression and function of P-gp/ABCB1 and BCRP/ABCG2 in the placenta and fetus. Expert Opin Drug Metab Toxicol. 2018;14:817-829.

59. Zheng S, Easterling TR, Hays K, et al. Tacrolimus placental transfer at delivery and neonatal exposure through breast milk. $\mathrm{Br} \mathrm{J}$ Clin Pharmacol. 2013;76:988-996.

60. Sun M, Kingdom J, Baczyk D, et al. Expression of the multidrug resistance P-glycoprotein, (ABCB1 glycoprotein) in the human placenta decreases with advancing gestation. Placenta. 2006;27:602-609.

61. Kamdem LK, Streit F, Zanger UM, et al. Contribution of CYP3A5 to the in vitro hepatic clearance of tacrolimus. Clin Chem. 2005;51:13741381 .

62. Stevens JC, Hines RN, Gu C, et al. Developmental expression of the major human hepatic CYP3A enzymes. J Pharmacol Exp Ther. 2003; 307:573-582.

63. de Wildt SN, Kearns GL, Leeder JS, et al. Cytochrome P450 3A: ontogeny and drug disposition. Clin Pharmacokinet. 1999;37: 485-505.

64. Wrighton SA, Brian WR, Sari MA, et al. Studies on the expression and metabolic capabilities of human liver cytochrome P450IIIA5 (HLp3). Mol Pharmacol. 1990;38:207-213.

65. Kociszewska-Najman B, Mazanowska N, Pietrzak B, et al. Low transfer of tacrolimus and its metabolites into colostrum of graft recipient mothers. Nutrients. 2018;10:E267.

66. Ono E, Dos Santos AM, Viana PO, et al. Immunophenotypic profile and increased risk of hospital admission for infection in infants born to female kidney transplant recipients. Am J Transpl. 2015; 15:1654-1665

67. Drozdowska-Szymczak A, Kociszewska-Najman B, Schreiber-Zamora $\mathrm{J}$, et al. Evaluation of selected markers of the immune system in children of renal transplant recipients. Transpl Proc. 2014;46:2703-2707.

68. Drozdowska-Szymczak A, Pietrzak B, Czaplińska N, et al. Immunological status of children born to female liver recipients. Ann Transpl. 2018;23:182-189.

69. Kociszewska-Najman B, Pietrzak B, Czaplinska N, et al. Congenital infections in neonates of women with liver or kidney transplants. Transpl Proc. 2016;48:1556-1560.

70. Farley DE, Shelby J, Alexander D, et al. The effect of two new immunosuppressive agents, FK506 and didemnin B, in murine pregnancy. Transplantation. 1991;52:106-110.

71. Kociszewska-Najman B, Pietrzak B, Schreiber-Zamora J, et al. Ultrasonography of the brain, abdomen, and heart in neonates born to liver or renal transplant recipient mothers. Ann Transpl. 2012;17:113119.

72. Schreiber-Zamora J, Kociszewska-Najman B, Borek-Dzieccioł B, et al. Neurological development of children born to liver transplant recipients. Transpl Proc. 2014;46:2798-2801.

73. Christopher V, Al-Chalabi T, Richardson PD, et al. Pregnancy outcome after liver transplantation: a single-center experience of 71 pregnancies in 45 recipients. Liver Transpl. 2006;12:1138-1143.

74. D'Souza R, Soete E, Silversides CK, et al. Pregnancy outcomes following cardiac transplantation. J Obstet Gynaecol Can. 2018;40:566-571.

75. Kanzaki Y, Kondoh E, Kawasaki K, et al. Pregnancy outcomes in liver transplant recipients: a 15-year single-center experience. J Obstet Gynaecol Res. 2016;42:1476-1482.

76. Yuksel Y, Tekin S, Yuksel D, et al. Pregnancy and delivery in the sequel of kidney transplantation: single-center study of 8 years' experience. Transpl Proc. 2017;49:546-550.

77. Akarsu M, Unek T, Avcu A, et al. Evaluation of pregnancy outcomes after liver transplantation. Transpl Proc. 2016;48:3373-3377.

78. Westbrook RH, Yeoman AD, Agarwal K, et al. Outcomes of pregnancy following liver transplantation: the King's College Hospital experience. Liver Transpl. 2015;21:1153-1159.

79. Armenti VT, Radomski JS, Moritz MJ, et al. Report from the national transplantation pregnancy Registry (NTPR): outcomes of pregnancy after transplantation. Clin Transpl. 2004:103-114.

80. Coscia LA, Constantinescu S, Davison JM, et al. Immunosuppressive drugs and fetal outcome. Bailliere's Best Pract Res Clin Obstet Gynaecol. 2014;28:1174-1187.

81. Armenti VT, Moritz MJ, Cardonick EH, et al. Immunosuppression in pregnancy: choices for infant and maternal health. Drugs. 2002;62: 2361-2375.
82. Jabiry-Zieniewicz Z, Szpotanska-Sikorska M, Pietrzak B, et al. Pregnancy outcomes among female recipients after liver transplantation: further experience. Transpl Proc. 2011;43:3043-3047.

83. Armenti VT, Herrine SK, Radomski JS, et al. Pregnancy after liver transplantation. Liver Transpl. 2000;6:671-685.

84. Carr DB, Larson AM, Schmucker BC, et al. Maternal hemodynamics and pregnancy outcome in women with prior orthotopic liver transplantation. Liver Transpl. 2000;6:213-221.

85. Nagy S, Bush MC, Berkowitz R, et al. Pregnancy outcome in liver transplant recipients. Obstet Gynecol. 2003;102:121-128.

86. Jabiry-Zieniewicz Z, Bobrowska K, Pietrzak B, et al. Mode of delivery in women after liver transplantation. Transpl Proc. 2007;39:27962799

87. Kubo S, Uemoto S, Furukawa H, et al. Pregnancy outcomes after living donor liver transplantation: results from a Japanese survey. Liver Transpl. 2014;20:576-583.

88. Dagher O, Alami Laroussi N, Carrier M, et al. Pregnancy after heart transplantation: a well-thought-out decision? The Quebec provincial experience - a multi-centre cohort study. Transpl Int. 2018;31:977-987.

89. Yuksel Y, Yuksel D, Yucetin L, et al. Use of tacrolimus during pregnancy after kidney transplantaion. Transpl Proc. 2019;51:2361-2366.

90. Mohamed-Ahmed O, Nelson-Piercy C, Bramham K, et al. Pregnancy outcomes in liver and cardiothoracic transplant recipients: a UK national cohort study. PLoS One. 2014;9:e89151.

91. Garcia-Donaire JA, Acevedo M, Gutiérrez MJ, et al. Tacrolimus as basic immunosuppression in pregnancy after renal transplantation. A single-center experience. Transpl Proc. 2005;37:3754-3755.

92. Al-Otaibi T, Gheith OA, Nagib AM, et al. Pregnancy after renal transplant: single center experience from the middle east in patients using different calcineurin inhibitors. Exp Clin Transpl. 2019;17:99-104.

93. Dinelli MIS, Ono E, Viana PO, et al. Growth of children born to renal transplanted women. Eur J Pediatr. 2017;176:1201-1207.

94. Jabiry-Zieniewicz Z, Cyganek A, Luterek K, et al. Pregnancy and delivery after liver transplantation. Transpl Proc. 2005;37:1197-1200.

95. Kamarajah SK, Arntdz K, Bundred J, et al. Outcomes of pregnancy in recipients of liver transplants. Clin Gastroenterol Hepatol. 2018;17: 1398-1404.

96. Madej A, Pietrzak B, Mazanowska N, et al. Hypertension in pregnant renal and liver transplant recipients. Transpl Proc. 2016;48:1730-1735.

97. Miller JC, Mastrobattista JM. Obstetrical and neonatal outcome in pregnancies after liver transplantation. Am J Parinatol. 2000;17:299-302.

98. Perales-Puchalt A, Vila Vives JM, López Montes J, et al. Pregnancy outcomes after kidney transplantation-immunosuppressive therapy comparison. J Matern Fetal Neonatal Med. 2012;25:1363-1366.

99. Songin T, Pietrzak B, Brawura-Biskupski-Samaha R, et al. Pregnancy after kidney and liver transplantation: its outcome and effect on the graft, mother, and neonate. Ann Transpl. 2014;19:660-666.

100. Ecevit C, Ünal F, Baran M, et al. Parenthood in pediatric liver transplant patients. Pediatr Transpl. 2012;16:346-349.

101. Aivazoglou L, Sass N, Junior HTS, et al. Pregnancy after renal transplantation: an evaluation of the graft function. Eur J Obstet Gynecol Reprod Biol. 2011;155:129-131.

102. Álvaro E, Jimenez LC, Palomo I, et al. Pregnancy and orthotopic liver transplantation. Transpl Proc. 2013;45:1966-1968.

103. Bethesda M. Report of the national high blood pressure education program working group on high blood pressure in pregnancy. Am J Obstet Gynecol. 2000;183:S1-S22.

104. Davison JM, Milne JE. Pregnancy and renal transplantation. Br J Urol. 1997;80(suppl 1):29-32.

105. Textor SC, Taler SJ, Canzanello VJ, et al. Posttransplantation hypertension related to calcineurin inhibitors. Liver Transpl. 2000;6:521-530.

106. Gardiner SM, March JE, Kemp PA, et al. Regional haemodynamic effects of cyclosporine A, tacrolimus and sirolimus in conscious rats. Br J Pharmacol. 2004;141:634-643.

107. Lim KBL, Schiano TD. Long-term outcome after liver transplantation. Mt Sinai J Med. 2012;79:169-189.

108. Canzanello VJ, Textor SC, Taler SJ, et al. Renal sodium handling with cyclosporin A and FK506 after orthotopic liver transplantation. $J$ Am Soc Nephrol. 1995;5:1910-1917.

109. Davison JM, Bailey DJ. Pregnancy following renal transplantation. $J$ Obstet Gynaecol Res. 2003;29:227-233. 
110. Armenti VT, Moritz MJ, Davison JM. Drug safety issues in pregnancy following transplantation and immunosuppression: effects and outcomes. Drug Saf. 1998;19:219-232.

111. Hou S. Pregnancy in chronic renal insufficiency and end-stage renal disease. Am J Kidney Dis. 1999;33:235-252.

112. Resch B, Mache CJ, Windhager T, et al. FK 506 and successful pregnancy in a patient after renal transplantation. Transpl Proc. 1998;30: $163-164$.

113. Schreiber-Zamora J, Szpotanska-Sikorska M, Czaplinska N, et al. Evaluation of the body mass index (BMI) in children born to organ transplant recipients. J Matern Fetal Neonatal Med. 2018;32:25122516.

114. Armenti VT, Radomski JS, Moritz MJ, et al. Report from the national transplantation pregnancy Registry (NTPR): outcomes of pregnancy after transplantation. Clin Transpl. 2003:131-141.

115. French AE, Soldin SJ, Soldin OP, et al. Milk transfer and neonatal safety of tacrolimus. Ann Pharmacother. 2003;37:815-818.

116. Gardiner SJ, Begg EJ. Breastfeeding during tacrolimus therapy. Obstet Gynecol. 2006;107:453-455.

117. Hiramatsu Y, Yoshida S, Kotani T, et al. Changes in the blood level, efficacy, and safety of tacrolimus in pregnancy and the lactation period in patients with systemic lupus erythematosus. Lupus. 2018;27:22452252.

118. Gouraud A, Bernard N, Millaret A, et al. Follow-up of tacrolimus breastfed babies. Transplantation. 2012;94:e38-40.

119. Izumi Y, Miyashita T, Migita K. Safety of tacrolimus treatment during pregnancy and lactation in systemic lupus erythematosus: a report of two patients. Tohoku J Exp Med. 2014;234:51-56.

120. Nure E, Pascale MM, Frongillo F, et al. Pregnancy after liver transplant: neonatal outcomes and long-term maternal follow-up. Transpl Proc. 2019;51:2948-2951.

121. Thiagarajan K, Arakali SR, Mealey KJ, et al. Safety considerations: breastfeeding after transplant. Prog Transpl. 2013;23:137-146.

122. van Gelder T, Hesselink DA. Mycophenolate revisited. Transpl Int 2015;28:508-515.

123. U.S. Food and Drug Administration. Product Monograph CellCept Roche Canada Web Site. 2018. Available at: https://www. rochecanada.com/PMs/CellCept/CellCept_PM_E.pdf. Accessed September 18, 2019.

124. Hardinger K, Brennan D. Maintenance Immunosuppressive Therapy in Kidney Transplantation in Adults UpToDate Web Site. 2018. Available at: https://www-uptodate-com.proxy.library.uu.nl/contents/ maintenance-immunosuppressive-therapy-in-kidney-transplantation-inadults? search $=$ mycophenolate \&topicRef $=3553 \&$ source $=$ see_link. Accessed September 23, 2019.

125. European Medicines Agency. Summary of Product Characteristics European Medicines Agency Web Site. 1996. Available at: https:// www.ema.europa.eu/en/documents/product-information/cellcept-eparproduct-information_en.pdf. Accessed January 27, 2020.

126. Mok CC, Chan PT, To CH. Anti-mullerian hormone and ovarian reserve in systemic lupus erythematosus. Arthritis Rheum. 2013;65: 206-210.

127. Eckardt K, Stahlmann R. Use of two validated in vitro tests to assess the embryotoxic potential of mycophenolic acid. Arch Toxicol. 2010;84: $37-43$.

128. Schmidt F, Eckardt K, Shakibaei M, et al. Effects of mycophenolic acid alone and in combination with its metabolite mycophenolic acid glucuronide on rat embryos in vitro. Arch Toxicol. 2013;87:361-370.

129. Jiang LL, Liu MH, Li JY, et al. Mycophenolic acid-induced developmental defects in zebrafish embryos. Int J Toxicol. 2016;35:712-718.

130. Sifontis NM, Coscia LA, Constantinescu S, et al. Pregnancy outcomes in solid organ transplant recipients with exposure to mycophenolate mofetil or sirolimus. Transplantation. 2006;82:1698-1702.

131. Hoeltzenbein M, Elefant E, Vial T. Teratogenicity of mycophenolate confirmed in a prospective study of the European network of teratology information services. Am J Med Genet A. 2012;158A:588-596.

132. Klieger-Grossmann C, Chitayat D, Lavign S, et al. Prenatal exposure to mycophenolate mofetil: an updated estimate. J Obstet Gynaecol Can. 2010;32:794-797.

133. Kylat RI. What is the teratogenic risk of mycophenolate? $J$ Pediatr Genet. 2017;6:111-114.
134. Lin AE, Singh KE, Strauss A, et al. An additional patient with mycophenolate mofetil embryopathy: cardiac and facial analyses. Am J Med Genet A. 2011;155A:748-756.

135. Parisi MA, Zayed H, Slavotinek AM, et al. Congenital diaphragmatic hernia and microtia in a newborn with mycophenolate mofetil (MMF) exposure: phenocopy for fryns syndrome or broad spectrum of teratogenic effects? Am J Med Genet Part A. 2009; 149:1237-1240.

136. Ang GS, Simpson SA, Reddy AR. Mycophenolate mofetil embryopathy may be dose and timing dependent. Am J Med Genet Part A. 2008; 146A:1963-1966.

137. Alsebayel MM, Abaalkhail FA, Alsebayel FM, et al. Congenital esophageal atresia and microtia in a newborn secondary to mycophenolate mofetil exposure during pregnancy: a case report and review of the literature. Am J Case Rep. 2018;19:523-526.

138. Perez-Aytes A, Ledo A, Boso V, et al. In Utero exposure to mycophenolate mofetil: a characteristic phenotype? Am J Med Genet Part A. 2008;146:1-7.

139. Anderka MT, Lin AE, Abuelo DN, et al. Reviewing the evidence for mycophenolate mofetil as a new teratogen: case report and review of the literature. Am J Med Genet Part A. 2009;149:1241-1248.

140. Jackson P, Paquette L, Watiker V, et al. Intrauterine exposure to mycophenolate mofetil and multiple congenital anomalies in a newborn: possible teratogenic effect. Am J Med Genet Part A. 2009;149:12311236.

141. Schoner K, Steinhard J, Figiel J, et al. Severe facial clefts in acrofacial dysostosis - a consequence of prenatal exposure to mycophenolate mofetil? Obstet Gynecol. 2008;111:483-486.

142. Pergola PE, Kancharla A, Riley DJ. Kidney transplantation during the first trimester of pregnancy: immunosuppression with mycophenolate mofetil, tacrolimus, and prednisone. Transplantation. 2001;71:994 997.

143. Martín MC, Cristiano E, Villanueva M, et al. Esophageal atresia and prenatal exposure to mycophenolate. Reprod Toxicol. 2014;50:117121

144. Le Ray C, Coulomb A, Elefant E, et al. Mycophenolate mofetil in pregnancy after renal transplantation: a case of major fetal malformations. Obstet Gynecol. 2004;103:1091-1094.

145. Koshy AN, Strong D, Earles G, et al. Congenital malformations with low-dose mycophenolate mofetil after kidney transplantation. Nephrology. 2010;15:134-135.

146. dei Malatesta MF, Rocca B, Gentile T, et al. A case of coloboma in a newborn to a woman taking mycophenolate mofetil in pregnancy after kidney transplantation. Transpl Proc. 2009;41:1407-1409.

147. Andrade Vila JH, Da Silva JP, Guilhen CJ, et al. Even low dose of mycophenolate mofetil in a mother recipient of heart transplant can seriously damage the fetus. Transplantation. 2008;86:369-370.

148. Tjeertes IF, Bastiaans DE, van Ganzewinkel CJ, et al. Neonatal anemia and hydrops fetalis after maternal mycophenolate mofetil use. $J$ Perinatol. 2007;27:62-64.

149. Kallen B, Westgren M, Aberg A, et al. Pregnancy outcome after maternal organ transplantation in Sweden. BJOG. 2005;112:904-909.

150. Zahra T, Seyyed Alireza T, Shirin S. Successful pregnancies in two orthotopic liver transplant (OLT) recipients in Iran; Two case reports. J Reprod Infertil. 2009;10:225-229.

151. Huang SY, Chueh HY, Shaw SW, et al. Sonographic diagnosis of fetal malformations associated with mycophenolate mofetil exposure in utero. Am J Obstet Gynecol. 2008;199:e6-8.

152. Velinov M, Zellers N. The fetal mycophenolate mofetil syndrome. Clin Dysmorphol. 2008;17:77-78.

153. El Sebaaly Z, Charpentier B, Snanoudj R. Fetal malformations associated with mycophenolate mofetil for lupus nephritis. Nephrol Dial Transpl. 2007;22:2722.

154. Ruiz-campillo C, Castillo F, Perapoch J, et al. Mycophenolate mofetil use for lupus nephritis during pregnancy: report of a case of fetal malformations and literature update. Internet J Gynecol Obstet. 2008;11:111 .

155. Perez-Aytes A, Marin-Reina P, Boso V, et al. Mycophenolate mofetil embryopathy: a newly recognized teratogenic syndrome. Eur $J \mathrm{Med}$ Genet. 2017:60:16-21.

156. Merlob P, Stahl B, Klinger G. Tetrada of the possible mycophenolate mofetil embryopathy: a review. Reprod Toxicol. 2009;28:105-108. 
157. Constantinescu SC L, Armenti D, Moritz M. Mycophenolic acid product discontinuation prior to conception: analysis of pregnancies in kidney transplant recipients [Abstract]. Am J Transpl. 2016;16(suppl 3): 228-228.

158. King RW, Baca MJ, Armenti VT, et al. Pregnancy outcomes related to mycophenolate exposure in female kidney transplant recipients. Am J Transpl. 2017;17:151-160.

159. Ghafari A, Sanadgol H. Pregnancy after renal transplantation: ten-year single-center experience. Transpl Proc. 2008;40:251-252.

160. Midtvedt K, Bergan S, Reisæter AV, et al. Exposure to mycophenolate and fatherhood. Transplantation. 2017;101:e214-e217.

161. European Medicines Agency. EMA Recommends Additional Measures to Prevent Use of Mycophenolate in Pregnancy Web Site. 2015. Available at: https://www.ema.europa.eu/en/news/ema-recommendsadditional-measures-prevent-use-mycophenolate-pregnancy. Accessed September 18, 2019.

162. Morken NH, Diaz-Garcia C, Reisaeter AV, et al. Obstetric and neonatal outcome of pregnancies fathered by males on immunosuppression after solid organ transplantation. Am J Transpl. 2015;15:1666-1673.

163. Jones A, Clary MJ, McDermott E, et al. Outcomes of pregnancies fathered by solid-organ transplant recipients exposed to mycophenolic acid products. Prog Transpl. 2013;23:153-157.

164. Xu LG, Jin LM, Zhu XF, et al. A report of 212 male renal transplant recipients who fathered 216 offspring after transplantation. Transplantation. 2008;86:1480-1481.

165. Lopez-Lopez I, Rodelo-Haad C, Agüera ML, et al. Administration of mycophenolic acid is not associated with malformations in descendants from kidney transplanted males. PLoS One. 2018;13:e0202589.

166. Constantinescu S, Pai A, Coscia LA, et al. Breast-feeding after transplantation. Best Pract Res Clin Obstet Gynaecol. 2014;28:1163-1173.

167. Coscia LA, Armenti DP, King RW, et al. Update on the teratogenicity of maternal mycophenolate mofetil. J Pediatr Genet. 2015;4:42-55.

168. van Gelder T, Hilbrands LB. Veldnorm: Gebruik Mycoffenolaat Bij Kinderwens Web Site. Available at: https://www.transplantatievereniging. $\mathrm{nl} /$ sites/www.transplantatievereniging.nl/files/Veldnorm\%20MMF\%20en \%20zwangerschap\%202\%20feb\%202018.pdf. Accessed February 7, 2020.
169. Kuypers DRJ, Van Mieghem T, Meijers B, et al. Updated manufacturer and European medicines agency recommendations on the use of mycophenolate acid: balancing the risks for male allograft recipients. Transplantation. 2016;100:e50-e51.

170. Combs J, Kagan A, Boelkins M, et al. Belatacept during pregnancy in renal transplant recipients: two case reports. Am J Transpl. 2018;18: 2079-2082.

171. Ma KK, Petroff MG, Coscia LA, et al. Complex chimerism: pregnancy after solid organ transplantation. Chimerism. 2013;4:71-77.

172. Rose C, Gill J, Zalunardo N, et al. Timing of pregnancy after kidney transplantation and risk of allograft failure. Am J Transpl. 2016;16: 2360-2367.

173. van Rood JJ, Claas F. Noninherited maternal HLA antigens: a proposal to elucidate their role in the immune response. Hum Immunol. 2000;61: 1390-1394.

174. Fischer T, Schobel H, Barenbrock M. Specific immune tolerance during pregnancy after renal transplantation. Eur J Obstet Gynecol Reprod Biol. 1996;70:217-219.

175. Capron A, Haufroid V, Wallemacq P. Intra-cellular immunosuppressive drugs monitoring: a step forward towards better therapeutic efficacy after organ transplantation? Pharmacol Res. 2016;111:610-618.

176. Bahmany S, de Wit LEA, Hesselink DA, et al. Highly sensitive and rapid determination of tacrolimus in peripheral blood mononuclear cells by liquid chromatography-tandem mass spectrometry. Biomed Chromatogr. 2019;33:e4416.

177. Lemaitre F, Antignac M, Fernandez C. Monitoring of tacrolimus concentrations in peripheral blood mononuclear cells: application to cardiac transplant recipients. Clin Biochem. 2013;46:1538-1541.

178. Han SS, Yang SH, Kim MC, et al. Monitoring the intracellular tacrolimus concentration in kidney transplant recipients with stable graft function. PLoS One. 2016;11:e0153491.

179. Capron A, Lerut J, Latinne D, et al. Correlation of tacrolimus levels in peripheral blood mononuclear cells with histological staging of rejection after liver transplantation: preliminary results of a prospective study. Transpl Int. 2012;25:41-47. 